\title{
Comparative analysis of the mitogenomes of two Corydoras (Siluriformes, Loricarioidei) with nine known Corydoras, and a phylogenetic analysis of Loricarioidei
}

\author{
Cheng-He Sun ${ }^{1,2}$, Qi Huang', Xiao-Shu Zeng', Sha Li', Xiao-Li Zhang', \\ Ya-Nan Zhang', Jian Liao', Chang-Hu Lu², Bo-Ping Han', Qun Zhang'
}

I Department of Ecology and Institute of Hydrobiology, Jinan University, Guangzhou 510632, China 2 College of Biology and the Environment, Nanjing Forestry University, Nanjing 210037, China 3 Chinese Sturgeon Research Institute, China Three Gorges Corporation, Yichang 443100, Hubei, China 4 Hubei Key Laboratory of Three Gorges Project for Conservation of Fishes, Yichang 443100, Hubei, China

Corresponding author: Qun Zhang (tqzhang@jnu.edu.cn)

Academic editor: Tihomir Stefanov | Received 22 October 2021 | Accepted 6 January 2022 | Published 24 January 2022

http://zoobank.org/7B1D7ADC-5E9D-4387-9EB8-4C1A6081E6A3

Citation: Sun C-H, Huang Q, Zeng X-S, Li S, Zhang X-L, Zhang Y-N, Liao J, Lu C-H, Han B-P, Zhang Q (2022) Comparative analysis of the mitogenomes of two Corydoras (Siluriformes, Loricarioidei) with nine known Corydoras, and a phylogenetic analysis of Loricarioidei. ZooKeys 1083: 89-107. https://doi.org/10.3897/zookeys.1083.76887

\begin{abstract}
Corydoras is a speciose catfish genus from South America with widely investigated phylogenetic and evolutionary relationships. The complete mitogenomes of $C$. aeneus and $C$. paleatus were sequenced, assembled, and annotated using next-generation sequencing. The genome arrangements, gene contents, genome structures, base compositions, evolutionary features, codon usage, and tRNA structures of the two mitogenomes were compared and analyzed with nine published mitogenomes of Corydoras. Phylogenetic analysis was performed using concatenated nucleotide sequences with 13 protein-coding genes and two rRNAs with 44 mitogenomes of Siluriformes. These results provide information on the mitogenomes of eleven Corydoras species and evolutionary relationships within the suborder Loricarioidei, which may be applicable for further phylogenetic and taxonomic studies on Siluriformes and Loricarioidei.
\end{abstract}

\section{Keywords}

Corydoras aeneus, Corydoras paleatus, genome sequencing, mitochondrial DNA, Phylogenetic tree

Copyright Cheng-He Sun et al. This is an open access article distributed under the terms of the Creative Commons Attribution License (CC BY 4.0), which permits unrestricted use, distribution, and reproduction in any medium, provided the original author and source are credited. 


\section{Introduction}

Fish mitochondrial DNA shares characteristics with other vertebrate mitochondrial DNA (Anderson et al. 1981; Manchado et al. 2007; Xu et al. 2011), e.g., small molecular weight, simple structure, and compact arrangement. It exists in the form of a covalently closed circular supercoil structure and contains heavy and light chains. The genetic material can be replicated, transcribed, and translated independently from the nuclear DNA in the cell. With few exceptions, fish mitochondrial DNA comprises 13 protein-coding genes (PCGs), 22 transfer RNA genes, two ribosomal RNA genes, original region of light-strand replication, and control region (D-loop) (Ojala et al. 1981; Gadaleta et al. 1989; Wolstenholme 1992 Simon et al. 1994; De Rijk et al. 1995). The mitochondrial DNA mutates rapidly, nearly 10 -fold faster than the nuclear DNA, and the fragment length and evolution rate differ for each gene, providing molecular evidence for studying different species (Brown et al. 1979; Pesole et al. 1999). In addition, mitochondrial DNA is highly heterogeneous and harbors the genetic characteristics associated with maternal traits (O’Brien 1971; Michot et al. 1990; Bartlett and Davidson 1991; Meyer 1993; Beheregaray and Sunnucks 2001; Liu et al. 2002; Yoshizawa and Johnson 2003). Hence, mitochondrial DNA can be used to identify fish groups at the molecular level and explore geographic distribution, species origin, and species differentiation (Avise et al. 1987; Kai et al. 2002; Hrbek et al. 2007). As fish are a large group with a complex origin in the vertebrate subphylum, studies on their phylogenetic and evolutionary relationships performed using traditional morphological methods often provide limited information. With advances in biotechnology, complete mitochondrial genome sequences have been determined as a useful tool to study the phylogeny and phylogeography of fish (Bermingham and Avise 1986; Xu et al. 2020).

Corydoras Lacépède, 1803, belongs to the order Siluriformes, suborder Loricarioidei, family Callichthyidae. Corydoras contains 175 valid species, which makes it the most species-rich genus of the family Callichthyidae (Lima and Britto 2020; Tencatt et al. 2021). The body of these fish is covered with bone plates, and the pectoral and dorsal fins have hard spines that can be used for protection. In addition, Corydoras can use the back end of their intestines, which is rich in blood vessels, to obtain oxygen from air taken in at the water surface, enabling survival under environmental stress, such as drought or insufficient dissolved oxygen content in water. Corydoras catfish are benthic omnivorous fish (Moreira et al. 2016b, 2017; Liu et al. 2019b, 2019c; Saitoh et al. 2003). Typically, Corydoras is active only during feeding, and otherwise hide while resting. Corydoras is primarily distributed in South America. Most species of Corydoras gather in the middle and lower reaches of the river where the current is relatively gentle, whereas a few live in the upper reaches of the river in rapids (Saitoh et al. 2003; Liu et al. 2019c). Corydoras is also valuable as an ornamental fish. Some phylogenetic relationships in Corydoras remain unclear. The number of species reported in relevant articles is small, which is not sufficient to reflect the phylogenetic variety of the genus Corydoras (Alexandrou et al. 2011; Lujan et al. 2015; Roxo et al. 2019). Therefore, a comprehensive understanding of the relationships between different species of Corydoras is essential. 
In this study, the complete mitogenomes of two species of Corydoras (Bronze corydoras $C$. aeneus Gill, 1858 and peppered corydoras $C$. paleatus Jenyns, 1842) were sequenced, assembled, and annotated. The genome organization, gene contents, repeat sequences, and tRNA structures of the eleven mitogenomes were compared and analyzed in combination with nine published mitogenomes of Corydoras (Saitoh et al. 2003; Moreira et al. 2016a, 2017; Liu et al. 2019a, b, c, d; Chen et al. 2020; Lv et al. 2020). Determining the similarities and differences in gene orders, genetic structures, base compositions, evolutionary features, and codon usage can provide molecular insights into the taxonomic and phylogenetic characteristics of the order Siluriformes. Based on these data, and those obtained from the NCBI database, we examined the phylogenetic relationships among species in the suborder Loricarioidei. We also evaluated the mitogenomes of eleven species of Corydoras and evolutionary relationships within the suborder Loricarioidei, thereby providing a valuable basis for further evolutionary studies on Siluriformes and Loricarioidei.

\section{Materials and methods}

\section{Sample collection and identification}

Single specimens of $C$. aeneus and $C$. paleatus were collected from the temple of Confucius flower and wood fish market, Nanjing city, Jiangsu province, China $\left(32^{\circ} 0{ }^{\prime} 27.1 " \mathrm{~N}\right.$, $118^{\circ} 50^{\prime} 11.5^{\prime \prime E}$ ) in June 2020 and identified based on their morphological characteristics, according to the latest taxonomic classification of fish (Popazoglo and Boeger 2000; Huysentruyt and Adriaens 2005a, b). Their geographic data and specific origins were unknown. All fresh tissues were immediately stored at $-80{ }^{\circ} \mathrm{C}$ in $95 \%$ ethanol until DNA extraction. Total DNA was extracted from the muscle tissue using a TIANamp Marine Animals DNA Kit DP324 (Tiangen Biotech Co., Ltd., Beijing, China) according to the manufacturer's instructions. DNA integrity and purity were evaluated by $1 \%$ agarose gel electrophoresis, and DNA purity was determined with a NanoDrop 2000 (NanoDrop Technologies, Wilmington, DE, USA). DNA concentrations were quantified using a Qubit ${ }^{\mathrm{R}}$ 2.0 Fluorometer (Life Technologies, Carlsbad, CA, USA). To ensure the accuracy of morphological identification, COI primers were designed based on the latest DNA barcoding database (NCBI and FishBase) and were amplified, sequenced, and compared. The COI sequences are provided in the Suppl. material 1. The results of the sequence alignment verify the accuracy of the morphological identification.

\section{Genome sequencing and assembly}

Next-generation sequencing was performed to determine the complete mitogenome sequence of the two species of Corydoras. The DNA libraries were sequenced on an Illumina sequencing platform by Novogene Co., Ltd. (Beijing, China). Briefly, the total DNA genome was quantified and fragmented into 250-base pair (bp) fragments using a Covaris M220 ultrasonic crushing system (Woburn, MA, USA) followed by whole- 
genome shotgun sequencing. According to the manufacturer's instructions, a library was constructed based on two indices using an Illumina TruSeq DNA PCR-Free HT kit (San Diego, CA, USA). An Illumina Novaseq 6000 platform was used for sequencing of 150 paired-end reads approximately $4 \mathrm{~Gb}$ in size. Clean reads were generated as previously described, and the remaining high-quality reads were assembled using SPADES V3.15.2 (Bankevich et al. 2012) (http://cab.spbu.ru/software/spades/) and SOAPDENOVO2 V2.01 (Luo et al. 2012) software. The preliminary assembly results were compared with the NT database, and looped sequences annotated as mitochondrial genomes were screened. CAP3 was used to merge the splicing results from the two software programs, and the assembly results were compared with those of related species using MUMMER v3.23 (Delcher et al. 2003). The mitogenome composition was confirmed, and a complete, high-quality map of the mitochondrial genome was obtained.

\section{Genome annotation and analysis}

The tRNA genes were verified using tRNASCAN-SE V1.3.1 (Lowe and Eddy 1997) with default settings for the vertebrate mitochondrial genetic code. The software, which integrates multiple analysis tools, can identify $99 \%$ of the tRNA genes with a very low number of false positives and predict the secondary structure of tRNAs. Protein-coding regions were re-identified using GLIMMER V3.0 (Ingram et al. 2009), and manual comparisons were performed using the SEQMAN program of LASERGENE V7.1 (Burland 2000) (DNAStar, Inc., Madison, WI, USA) based on the PCGs of nine species of Corydoras and translated into putative proteins via GenBank. The non-coding RNAs were verified using RFAM V12.0 (Griffiths-Jones et al. 2003) and INFERNAL V1.1 (Nawrocki and Eddy 2013). The rRNA genes were assumed to extend to the boundaries of flanking genes, similar to the homologous regions of other published mitogenomes of Corydoras in GenBank. The MITOS WebServer (http://mitos2.bioinf.uni-leipzig.de/ index.py) and MitoFish (Iwasaki et al. 2013) (http://mitofish.aori.u-tokyo.ac.jp/) online tools were used for the final annotation of the entire mitogenome sequence of the two species of Corydoras, and the annotated mitogenomes were compared with nine published mitogenomes of Corydoras. Base compositions, genetic distances, and relative synonymous codon usage values were determined using MEGA V7.0 (Kumar et al. 1994). A graph comparing the relative synonymous codon usage was drawn using PHYLOSUITE V1.2.2 (Zhang et al. 2020). Strand asymmetry was analyzed using the formula: AT-skew $=(\mathrm{A}-\mathrm{T}) /(\mathrm{A}+\mathrm{T})$. The numbers of non-synonymous $(\mathrm{Ka})$ and synonymous $(\mathrm{Ks})$ substitutions and the ratio of $\mathrm{Ka} / \mathrm{Ks}$ and nucleotide diversity for the nine species of Corydoras were calculated using DNASP 5.1 (Librado and Rozas 2009). The MitoFish (http:// mitofish.aori.u-tokyo.ac.jp/) online tool was used to generate circular mitogenome maps.

\section{Phylogenetic analysis}

Phylogenetic trees for the eleven mitogenomes of Corydoras within the family Callichthyidae and Suborder Loricarioidei were constructed by aligning 13 PCGs and two 
rRNA sequences with those of 42 species of Loricarioidei, 29 species from Loricariidae, and one species from Trichomycteridae (Table 1). The mitogenomes of Pterocryptis cochinchinensis (Resende et al. 2016) and Silurus asotus (Nakatani et al. 2011) (accession no. NC_027107.1 and NC_015806.1, respectively, suborder Siluroidei) were included as outgroups to root the Loricarioidei tree. All operations were performed in PHYLOSUITE V1.2.2 (Zhang et al. 2020) software package. The nucleotide sequences of 13 PCGs from 44 mitogenomes were aligned in batches with MAFFT V7.313 (Katoh and Standley 2013) (https://mafft.cbrc.jp/alignment/server/) using the

Table I. Information on 44 Siluriformes species evaluated in the study.

\begin{tabular}{|c|c|c|c|c|c|c|}
\hline No. & Suborder & Family & Taxa & GenBank accession no. & Length (bp) & Location/Reference \\
\hline 1 & Loricarioidei & Callichthyidae & Corydoras aeneus & MZ571336 & 16604 & This study \\
\hline 2 & & & Corydoras agassizii & MN641875.1 & 16538 & Lv et al. 2020 \\
\hline 3 & & & Corydoras arcuatus & NC_049096.1 & 16177 & Liu et al. $2019 \mathrm{~d}$ \\
\hline 4 & & & Corydoras duplicareus & NC_049095.1 & 16632 & Liu et al. 2019a \\
\hline 5 & & & Corydoras nattereri & KT239008.1 & 16557 & Moreira et al. 2016a \\
\hline 6 & & & Corydoras paleatus & MZ571337 & 16320 & This study \\
\hline 7 & & & Corydoras panda & NC_049097.1 & 16398 & Liu et al. $2019 b$ \\
\hline 8 & & & Corydoras rabauti & NC_004698.1 & 16711 & Saitoh et al. 2003 \\
\hline 9 & & & Corydoras schwartzi & KT239007.1 & 15671 & Moreira et al. 2017 \\
\hline 10 & & & Corydoras sterbai & NC_048967.1 & 16520 & Liu et al. 2019c \\
\hline 11 & & & Corydoras trilineatus & NC_049098.1 & 15359 & Chen et al. 2020 \\
\hline 12 & & & Hoplosternum littorale & KX087170.1 & 16262 & Parente et al. 2018 \\
\hline 13 & & Loricariidae & Ancistomus snethlageae & KX087166.1 & 16464 & Moreira et al. 2017 \\
\hline 14 & & & Ancistrus cryptophthalmus & MF804392.1 & 16333 & Lv et al. 2020 \\
\hline 15 & & & Ancistrus multispinis & KT239006.1 & 16539 & Moreira 2018 \\
\hline 16 & & & Ancistrus temminckii & NC_051963.1 & 16439 & Meng et al. 2021 \\
\hline 17 & & & Aphanotorulus emarginatus & KT239019.1 & 16597 & Moreira et al. 2017 \\
\hline 18 & & & Baryancistrus xanthellus & KX087167.1 & 16167 & Moreira et al. 2017 \\
\hline 19 & & & Dekeyseria amazonica & KX087168.1 & 16409 & Moreira 2018 \\
\hline 20 & & & Hemipsilichthys nimius & KT239011.1 & 16477 & Moreira et al. 2017 \\
\hline 21 & & & Hisonotus thayeri & KX087173.1 & 16269 & Moreira et al. 2017 \\
\hline 22 & & & Hypancistrus zebra & KX611143.1 & 16202 & Magalhães et al. 2017 \\
\hline 23 & & & Hypoptopoma incognitum & NC_028072.1 & 16313 & Moreira et al. $2016 b$ \\
\hline 24 & & & Hypostomus affinis & KT239013.1 & 16330 & Moreira et al. 2017 \\
\hline 25 & & & Hypostomus ancistroides & NC_052710.1 & 16422 & Rocha-Reis et al. 2020 \\
\hline 26 & & & Hypostomus francisci & NC_045188.1 & 16916 & Pereira et al. 2019 \\
\hline 27 & & & Hypostomus plecostomus & NC_025584.1 & 16562 & Liu et al. 2016 \\
\hline 28 & & & Kronichthys heylandi & KT239014.1 & 16632 & Moreira et al. 2017 \\
\hline 29 & & & Loricaria cataphracta & KX087174.1 & 16831 & Moreira et al. 2017 \\
\hline 30 & & & Loricariichthys castaneus & KT239015.1 & 16521 & Moreira et al. 2017 \\
\hline 31 & & & Loricariichthys platymetopon & KT239018.1 & 16521 & Moreira et al. 2017 \\
\hline 32 & & & Neoplecostomus microps & KX087175.1 & 16523 & Moreira et al. 2017 \\
\hline 33 & & & Otocinclus affinis & MT323116.1 & 16501 & Zhang et al. 2021 \\
\hline 34 & & & Pareiorhaphis garbei & KX087178.1 & 16630 & Moreira et al. 2017 \\
\hline 35 & & & Parotocinclus maculicauda & KX087179.1 & 16541 & Moreira et al. 2017 \\
\hline 36 & & & Peckoltia furcata & KX087180.1 & 16497 & Moreira et al. 2017 \\
\hline 37 & & & Pterygoplichthys anisitsi & KT239003.1 & 16636 & Parente et al. 2017 \\
\hline 38 & & & Pterygoplichthys disjunctivus & NC_015747.1 & 16667 & Nakatani et al. 2011 \\
\hline 39 & & & Pterygoplichthys pardalis & KT239016.1 & 16822 & Moreira et al. 2017 \\
\hline 40 & & & Schizolecis guntheri & KT239017.1 & 16611 & Moreira et al. 2017 \\
\hline 41 & & & Sturisomatichthys panamensis & NC_045877.1 & 16526 & Ren et al. 2019 \\
\hline 42 & & Trichomycteridae & Trichomycterus areolatus & AP012026.1 & 16657 & Nakatani et al. 2011 \\
\hline 43 & Siluroidei & Siluridae & Pterocryptis cochinchinensis & NC_027107.1 & 16826 & Resende et al. 2016 \\
\hline 44 & & & Silurus asotus & NC_015806.1 & 16593 & Nakatani et al. 2011 \\
\hline
\end{tabular}


codon alignment mode. The results were optimized using MACSE V2.03 (Ranwez et al. 2018). The nucleotide sequences of two rRNAs were aligned using the online tool MAFFT with default settings. Ambiguously aligned regions were removed via GBLOCKS $0.91 \mathrm{~b}$ with default settings. The resulting alignments were concatenated into a single dataset with PHYLOSUITE. The best partition schemes and optimal substitution models were selected by MODELFINDER (Kalyaanamoorthy et al. 2017) with the greedy algorithm and Bayesian information criterion (Watanabe 2013). The best substitution models applied to each partition are listed in Suppl. material 1: Table S1. Phylogenetic trees were constructed using two inference methods: maximum likelihood (ML) and Bayesian inference (BI). ML analyses were performed with IQ-TREE V1.6.8 with the models selected for each partition, and 1,000 bootstrap replicates were used to estimate node reliability. Bayesian analyses were performed using MRBAYES V3.2.6 (Huelsenbeck and Ronquist 2001). One million generations of two independent runs were performed with four chains and sampling trees every 100 generations. The initial $25 \%$ of trees generated prior to reaching stable log-likelihood values were discarded as burn-in. The remaining trees were used to calculate the Bayesian posterior probabilities. The resulting phylogenetic trees and gene orders were visualized and edited using iTOL (Letunic and Bork 2016).

\section{Results and discussion}

\section{Genome structure and organization}

The complete mitogenomes of $C$. aeneus and C. paleatus comprising 16,604 and 16,593 bp, respectively, were submitted to GenBank (accession nos. MZ571336 and MZ571337, respectively) (Fig. 1, Table 2). The two mitogenomes were circular and contained 37 mitochondrial genes (13 PCGs, 22 tRNA genes, and two rRNA genes)
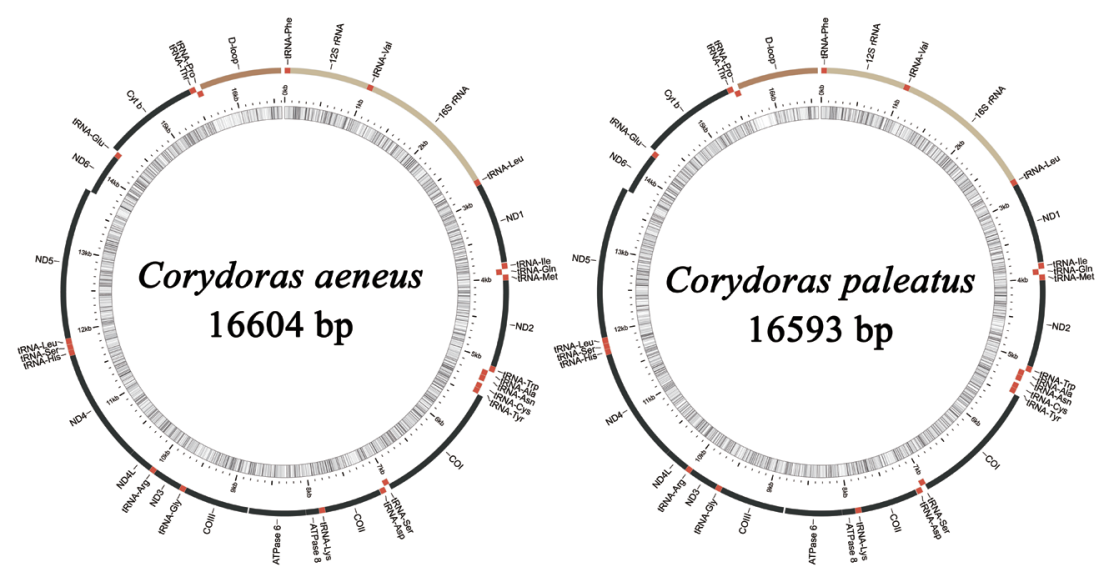

Figure I. Gene maps of the two newly sequenced Corydoras species. 
Table 2. Characteristic features of Corydoras aeneus and Corydoras paleatus mitogenomes (+ denotes heavy strand; - denotes light strand).

\begin{tabular}{|c|c|c|c|c|c|c|c|c|c|c|c|c|c|c|}
\hline \multirow{3}{*}{ Feature } & \multicolumn{4}{|c|}{ Position } & \multicolumn{2}{|c|}{ Length (bp) } & \multicolumn{2}{|c|}{ Start codons } & \multicolumn{2}{|c|}{ Stop codons } & \multirow{3}{*}{ Anticodon } & \multirow{3}{*}{ Strand } & \multicolumn{2}{|c|}{ Intergenic nucleotides } \\
\hline & \multicolumn{2}{|c|}{ C. aeneus } & \multicolumn{2}{|c|}{ C. paleatus } & \multirow{2}{*}{ C. aeneus } & \multirow{2}{*}{ C.paleatus } & \multirow{2}{*}{ C. $a$} & \multirow{2}{*}{ C.p } & \multirow{2}{*}{ C. $a$} & \multirow{2}{*}{$C \cdot p$} & & & \multirow[b]{2}{*}{ C. $a$} & \multirow[b]{2}{*}{$C . p$} \\
\hline & From & to & From & to & & & & & & & & & & \\
\hline tRNA-Phe & 1 & 68 & 1 & 68 & 68 & 68 & & & & & GAA & + & 0 & 0 \\
\hline $12 S$ rRNA & 69 & 1014 & 69 & 1013 & 946 & 945 & & & & & & + & 0 & 0 \\
\hline tRNA-Val & 1015 & 1086 & 1014 & 1085 & 72 & 72 & & & & & TAC & + & 0 & 0 \\
\hline $16 \mathrm{~S}$ rRNA & 1087 & 2757 & 1086 & 2753 & 1671 & 1668 & & & & & & + & 0 & 0 \\
\hline tRNA-Leu & 2758 & 2832 & 2754 & 2828 & 75 & 75 & & & & & TAA & + & 0 & 0 \\
\hline ND1 & 2833 & 3804 & 2829 & 3800 & 972 & 972 & ATG & ATG & TAG & TAG & & + & 8 & 8 \\
\hline tRNA-Ile & 3813 & 3884 & 3809 & 3880 & 72 & 72 & & & & & GAT & + & -2 & -2 \\
\hline tRNA-Gln & 3883 & 3953 & 3879 & 3949 & 71 & 71 & & & & & TTG & - & -1 & -1 \\
\hline tRNA-Met & 3953 & 4022 & 3949 & 4018 & 70 & 70 & & & & & CAT & + & 0 & 0 \\
\hline ND2 & 4023 & 5067 & 4019 & 5063 & 1045 & 1045 & ATG & ATG & $\mathrm{T}$ & $\mathrm{T}$ & & + & 0 & 0 \\
\hline tRNA-Trp & 5068 & 5139 & 5064 & 5134 & 72 & 71 & & & & & TCA & + & 1 & 1 \\
\hline tRNA-Ala & 5141 & 5209 & 5136 & 5204 & 69 & 69 & & & & & TGC & - & 1 & 1 \\
\hline tRNA-Asn & 5211 & 5283 & 5206 & 5278 & 73 & 73 & & & & & GTT & - & 30 & 31 \\
\hline tRNA-Cys & 5314 & 5380 & 5310 & 5377 & 67 & 68 & & & & & GCA & - & -1 & -1 \\
\hline tRNA-Tyr & 5380 & 5449 & 5377 & 5446 & 70 & 70 & & & & & GTA & - & 1 & 1 \\
\hline COI & 5451 & 7010 & 5448 & 7007 & 1560 & 1560 & GTG & GTG & AGG & AGG & & + & -13 & -13 \\
\hline tRNA-Ser & 6998 & 7068 & 6995 & 7065 & 71 & 71 & & & & & TGA & - & 4 & 4 \\
\hline tRNA-Asp & 7073 & 7141 & 7070 & 7138 & 69 & 69 & & & & & GTC & + & 4 & 6 \\
\hline COII & 7146 & 7836 & 7145 & 7835 & 691 & 691 & ATG & ATG & $\mathrm{T}$ & $\mathrm{T}$ & & + & 0 & 0 \\
\hline tRNA-Lys & 7837 & 7910 & 7836 & 7909 & 74 & 74 & & & & & TTT & + & 1 & 1 \\
\hline ATPase 8 & 7912 & 8079 & 7911 & 8078 & 168 & 168 & ATG & ATG & TAA & TAA & & + & -10 & -10 \\
\hline ATPase 6 & 8070 & 8753 & 8069 & 8752 & 684 & 684 & ATG & ATG & TAA & TAA & & + & 17 & 21 \\
\hline COIII & 8771 & 9554 & 8774 & 9557 & 784 & 784 & ATG & ATG & $\mathrm{T}$ & $\mathrm{T}$ & & + & 0 & 0 \\
\hline tRNA-Gly & 9555 & 9626 & 9558 & 9629 & 72 & 72 & & & & & TCC & + & 0 & 0 \\
\hline ND3 & 9627 & 9975 & 9630 & 9978 & 349 & 349 & ATG & ATG & $\mathrm{T}$ & $\mathrm{T}$ & & + & 0 & 0 \\
\hline tRNA-Arg & 9976 & 10045 & 9979 & 10048 & 70 & 70 & & & & & TCG & + & 0 & 0 \\
\hline ND4L & 10046 & 10342 & 10049 & 10345 & 297 & 297 & ATG & ATG & TAA & TAA & & + & -7 & -7 \\
\hline ND4 & 10336 & 11716 & 10339 & 11719 & 1381 & 1381 & ATG & ATG & $\mathrm{T}$ & $\mathrm{T}$ & & + & 0 & 0 \\
\hline tRNA-His & 11717 & 11786 & 11720 & 11789 & 70 & 70 & & & & & GTG & + & 0 & 0 \\
\hline tRNA-Ser & 11787 & 11853 & 11790 & 11856 & 67 & 67 & & & & & GCT & + & 1 & 1 \\
\hline tRNA-Leu & 11855 & 11927 & 11858 & 11930 & 73 & 73 & & & & & TAG & + & 0 & 0 \\
\hline ND5 & 11928 & 13754 & 11931 & 13757 & 1827 & 1827 & ATG & ATG & TAA & TAA & & + & -4 & -4 \\
\hline ND6 & 13751 & 14266 & 13754 & 14269 & 516 & 516 & ATG & ATG & TAA & TAA & & - & 0 & 0 \\
\hline tRNA-Glu & 14267 & 14335 & 14270 & 14337 & 69 & 68 & & & & & TTC & - & 2 & 3 \\
\hline Cyt b & 14338 & 15475 & 14341 & 15478 & 1138 & 1138 & ATG & ATG & $\mathrm{T}$ & $\mathrm{T}$ & & + & 0 & 0 \\
\hline tRNA-Thr & 15476 & 15548 & 15479 & 15550 & 73 & 72 & & & & & TGT & + & -2 & -2 \\
\hline tRNA-Pro & 15547 & 15616 & 15549 & 15618 & 70 & 70 & & & & & TGG & - & 0 & 0 \\
\hline D-loop & 15617 & 16604 & 15619 & 16593 & 988 & 975 & & & & & & & 0 & 0 \\
\hline
\end{tabular}

and one D-loop. The position of each gene in the mitogenome was identical to that in other species of Corydoras (Saitoh et al. 2003; Moreira et al. 2016a, 2017; Liu et al. 2019a, b, c, d; Chen et al. 2020; Lv et al. 2020). One of the 13 PCGs (ND6) and eight tRNAs (tRNA-Ala, tRNA-Cys, tRNA-Glu, tRNA-Asn, tRNA-Pro, tRNA-Gln, tRNA-Ser(TGA), and tRNA-Tyr) were encoded by the light chain (-), whereas the other 28 genes, including 12 PCGs, 14 tRNAs, two rRNAs, and one D-loop, were encoded by the heavy chain (+) (Fig. 1, Table 2). The 44 mitogenomes of Siluriformes (Nakatani et al. 2011; Liu et al. 2016; Moreira et al. 2016b, 2018; Resende et al. 2016; 
Magalhães et al. 2017; Parente et al. 2017; Parente et al. 2018; Pereira et al. 2019; Ren et al. 2019; Rocha-Reis et al. 2020; Meng et al. 2021; Zhang et al. 2021) used in this study were compared, and the gene composition and order were consistent (Suppl. material 1: Fig. S1). The nucleotide composition of the two entire mitogenomes was as follows: $C$. aeneus $\mathrm{A}=5417$ (32.63\%), $\mathrm{T}=4299$ (25.89\%), $\mathrm{G}=2451(14.76 \%), \mathrm{C}$ $=4437(26.72 \%)$ and $C$. paleatus $\mathrm{A}=5380(32.42 \%), \mathrm{T}=4282(25.81 \%), \mathrm{G}=2481$ (14.95\%), $\mathrm{C}=4450$ (26.82\%). The two mitogenomes (values for $C$. aeneus followed by values for C. paleatus) had high A+T contents of 58.52\% and $58.23 \%$ (Suppl. material 1: Table S2), including 58.08\% and 57.67\% in PCGs, $56.97 \%$ and $57.04 \%$ in tRNA genes, $59.70 \%$ and $59.10 \%$ in $16 \mathrm{~S}$ rRNA, $55.30 \%$ in $12 \mathrm{~S}$ rRNA, and $67.51 \%$ and $68.21 \%$ in the D-loop, respectively, which agrees with the typical base bias of fish mitogenomes (Gadaleta et al. 1989; Manchado et al. 2007; Xu et al. 2011). The overall AT and GC skew values in the entire mitogenome of $C$. aeneus were 0.115 and -0.288 and in $C$. paleatus were 0.114 and -0.284 , respectively. The GC skew value of the eleven mitogenomes of Corydoras, except for tRNA, was slightly negative $(-0.014$ to -0.288), showing a higher occurrence of $\mathrm{C}$ than of $\mathrm{G}$. In contrast, AT skew value, except for the second codon position, was slightly positive (0.028 to 0.379$)$, showing a higher content of A than of T. The K2P genetic distances of the eleven mitogenomes of Corydoras were all less than 0.12 (Suppl. material 1: Table S3). C. nattereri and C. sterbai and $C$. nattereri and $C$. trilineatus showed the largest $\mathrm{K} 2 \mathrm{P}$ genetic distances among the eleven species of Corydoras.

\section{Protein-coding genes}

The 13 PCGs of the two new mitogenomes and those of the previously published nine mitogenomes of Corydoras contained COI-COIII, ND1-ND6, ND4L, two ATPases, and one Cyt-b, similar to that in other Siluriformes (Nakatani et al. 2011; Liu et al. 2016; Moreira et al. 2016b; Resende et al. 2016; Magalhães et al. 2017; Parente et al. 2017; Moreira 2018; Parente et al. 2018; Pereira et al. 2019; Ren et al. 2019; Rocha-Reis et al. 2020; Meng et al. 2021; Zhang et al. 2021). The total lengths of PCGs in the eleven mitogenomes of Corydoras were 11,400-11,414 bp, accounting for $67.84-69.24 \%$ of the entire mitogenome. Similar to the mitogenomes of other species of Loricarioidei, ND5 and ATPase 8 were largest (1,827 bp) and smallest (168 bp), respectively. Most PCGs stringently start with an ATG start codon, except for all COIs, which start with GTG, C. nattereri COIII (Moreira et al. 2016a) which starts with GCA, and C. schwartzi COII (Moreira et al. 2017), which starts with CCA (Suppl. material 1: Table S4). Most PCGs are stringently terminated by the stop codon TAR (TAA/TAG) or an incomplete stop codon T, except for all COIs, which terminate with AGG and C. schwartzi ATPase 6 and C. nattereri ND3, which terminate with TA. The presence of a truncated stop codon is common among vertebrate mitochondrial genes and is thought to be introduced by posttranscriptional poly-adenylation.

Similar to most previously sequenced members of Loricarioidei, the AT-skews (0.033 to 0.052$)$ and GC-skews (-0.268 to -0.299$)$ of the PCGs were similar among 
the eleven species of Corydoras (Suppl. material 1: Table S2). Summaries of the relative synonymous codon usage and the number of amino acids in the annotated PCGs are presented in Suppl. material 1: Figs S2, S3. The PCGs of the eleven mitogenomes of Corydoras (Saitoh et al. 2003; Moreira et al. 2016a, 2017; Liu et al. 2019a, b, c, d; Chen et al. 2020; Lv et al. 2020) translate into 3,798-3,802 codons and showed very similar codon usage, excluding the stop codons (26-28 bp). Ile (310.82 \pm 2.69 codons), Thr (312.64 \pm 2.27 codons), Ala (312.73 \pm 3.08 codons), and Leu1 (CUN) ( $475.45 \pm 12.89$ codons) were the four most predominant codon families and may be associated with the coding function of the chondriosome. In contrast, Cys (24.91 \pm 0.79 codons) and Ser1 (AGN) (52.18 \pm 0.83 codons) had the smallest number of codons. $\mathrm{A} / \mathrm{T}$ rather than $\mathrm{G} / \mathrm{C}$ bias was observed in the third position, as almost all frequently used codons ended with $\mathrm{A} / \mathrm{T}$. The synonymous codon preferences for the eleven species of Corydoras were conserved, possibly because of the close relationships among members of this genus.

To reveal the evolutionary pattern of the PCGs, the Ka/Ks, nucleotide diversity, and $\mathrm{K} 2 \mathrm{P}$ genetic distance across all mitogenomes of Corydoras were calculated for each aligned PCG. The K2P genetic distances of 13 PCGs were all less than 0.12 (Fig. 2a). Among the PCGs detected, ND4 and ATPase 8 showed the largest K2P genetic distance among the eleven species of Corydoras, followed by ND2 and ND3. The nucleotide diversity of the 13 PCGs was less than 0.11 (Fig. 2b). ND4 showed the highest nucleotide diversity, whereas COII showed the lowest diversity. To investigate the selective pressure across species of Corydoras, the $\mathrm{Ka} / \mathrm{Ks}$ ratios of the PCGs of each mitogenome were estimated (Fig. 2c). The Ka/Ks value was highest for ND6, followed by ND2; the lowest values were observed for COI, COIII, ND1, and ND4L. All 13 PCGs showed $\mathrm{Ka} / \mathrm{Ks}<<1$, suggesting that all PCGs of Corydoras evolved under purifying selection.

\section{tRNAs, ribosomal RNAs, and control region}

The total lengths of the 22 tRNA genes ranged from 1,438 (C. schwartzi) to 1,561 bp (C. arcuatus and C. panda), whereas individual tRNA genes typically ranged from 58 to $75 \mathrm{bp}$. All tRNA genes displayed the expected cloverleaf secondary structures with normal base pairing, except for tRNA-Ser(GCT), which lacked the DHU stem (Suppl. material 1: Fig. S4), forming a loop commonly found in other vertebrates (Ojala et al. 1981; Gadaleta et al. 1989; Wolstenholme 1992). The A+T contents of these tRNAs were $56.55-57.58 \%$. All AT-skew and GC-skew values were slightly positive, indicating a slight bias toward the use of A and G in the tRNAs (Suppl. material 1: Table S2). These rRNA genes are between tRNA-Phe and tRNA-Leu(TAA) and are separated by tRNAVal. The average total size of the two rRNAs was $2,614 \mathrm{bp}$, and the average A+T content was $57.89 \%$. Like the tRNAs, all AT-skew values were positive, whereas all GC-skew values were negative, indicating that rRNAs favor $\mathrm{C}$ compared to tRNAs in Corydoras.

The control region (D-loop), also known as the $\mathrm{A}+\mathrm{T}$ rich region that contains hypervariable non-coding sequences and regulates the replication and transcription of mitochondrial DNA, is the largest non-coding region and is located between tRNA- 

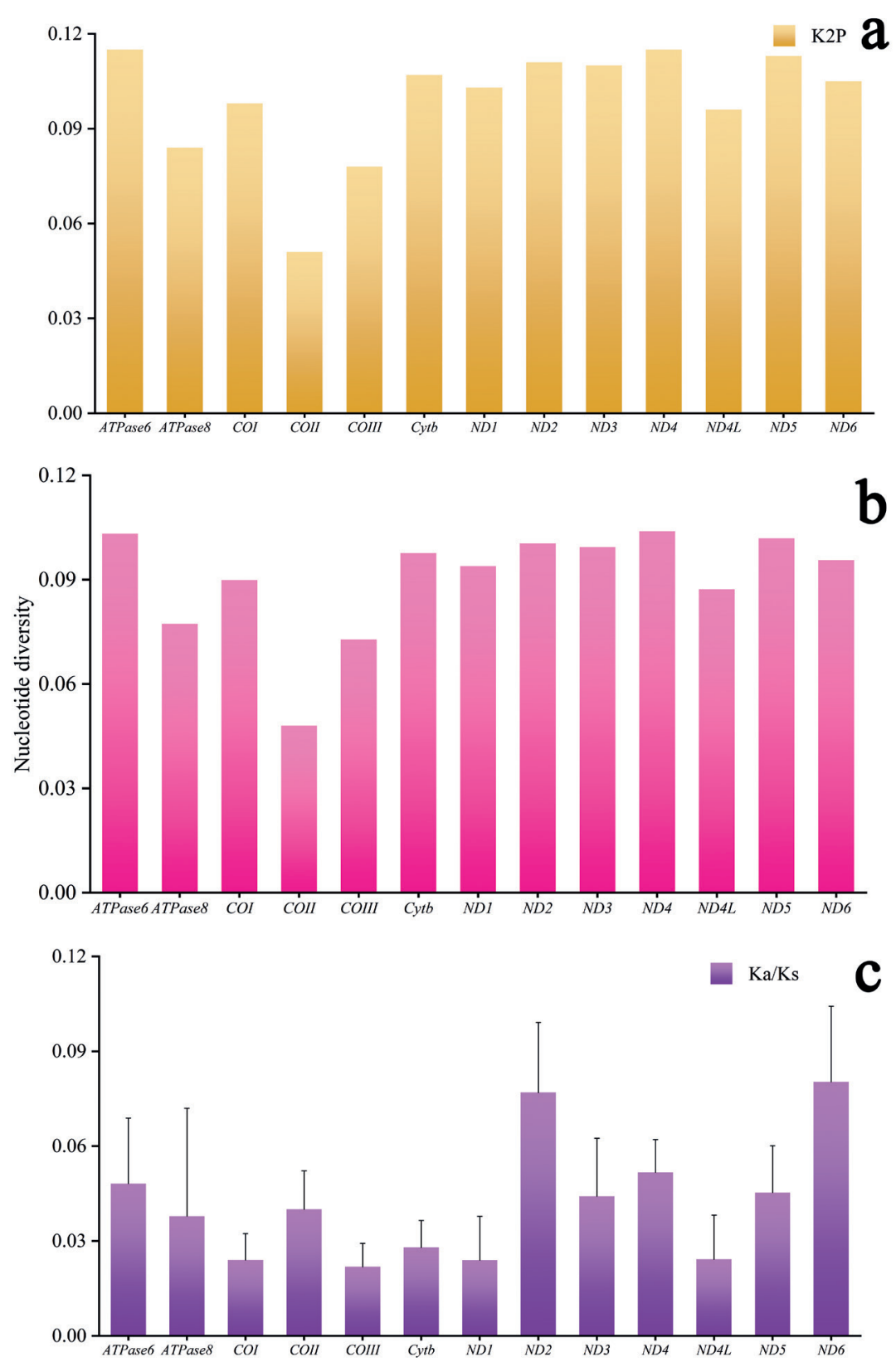

Figure 2. K2P genetic distance $\mathbf{a}$ nucleotide diversity $\mathbf{b} \mathrm{Ka} / \mathrm{Ks}$ ratio $\mathbf{c}$ analyses of protein-coding genes among the eleven Corydoras mitogenomes.

Pro and tRNA-Phe in these mitogenomes. Compared with PCGs, the D-loop displayed a higher mutation rate and the highest variation throughout the mitogenome; thus, this region is dominant and can be used to evaluate intraspecies variations. The 
D-loops in the eleven species of Corydoras were 718-1,218 bp. Compared with the other four regions (entire genome, PCGs, tRNAs, and rRNAs), the control region showed the highest $\mathrm{A}+\mathrm{T}$ content, ranging from $66.77 \%$ to $71.87 \%$. Like the rRNAs, all AT-skew values were positive, and all GC-skew values were negative.

\section{Phylogenetic analysis}

To determine the phylogenetic relationships within the suborder Loricarioidei and family Callichthyidae, we obtained the concatenated nucleotide sequences of 13 PCGs and two rRNAs from 42 species of Loricarioidei. Phylogenetic analyses based on both ML and BI methods revealed same topologies, which also generally agreed with those presented in previous studies (Alexandrou et al. 2011; Lujan et al. 2015; Moreira et al. 2017; Roxo et al. 2019) (Figs 3, 4). These analyses confirmed that the genus Corydoras was part of the monophyletic family Callichthyidae.

Both Callichthyidae and Loricariidae were recovered as monophyletic with very high support values (BI posterior probabilities, $\mathrm{PP}=1$; $\mathrm{ML}$ bootstrap, $\mathrm{BS}=100$ ). The 44 species of Siluriformes were divided into four major clades corresponding to the families Siluridae Callichthyidae, Trichomycteridae, and Loricariidae. The target

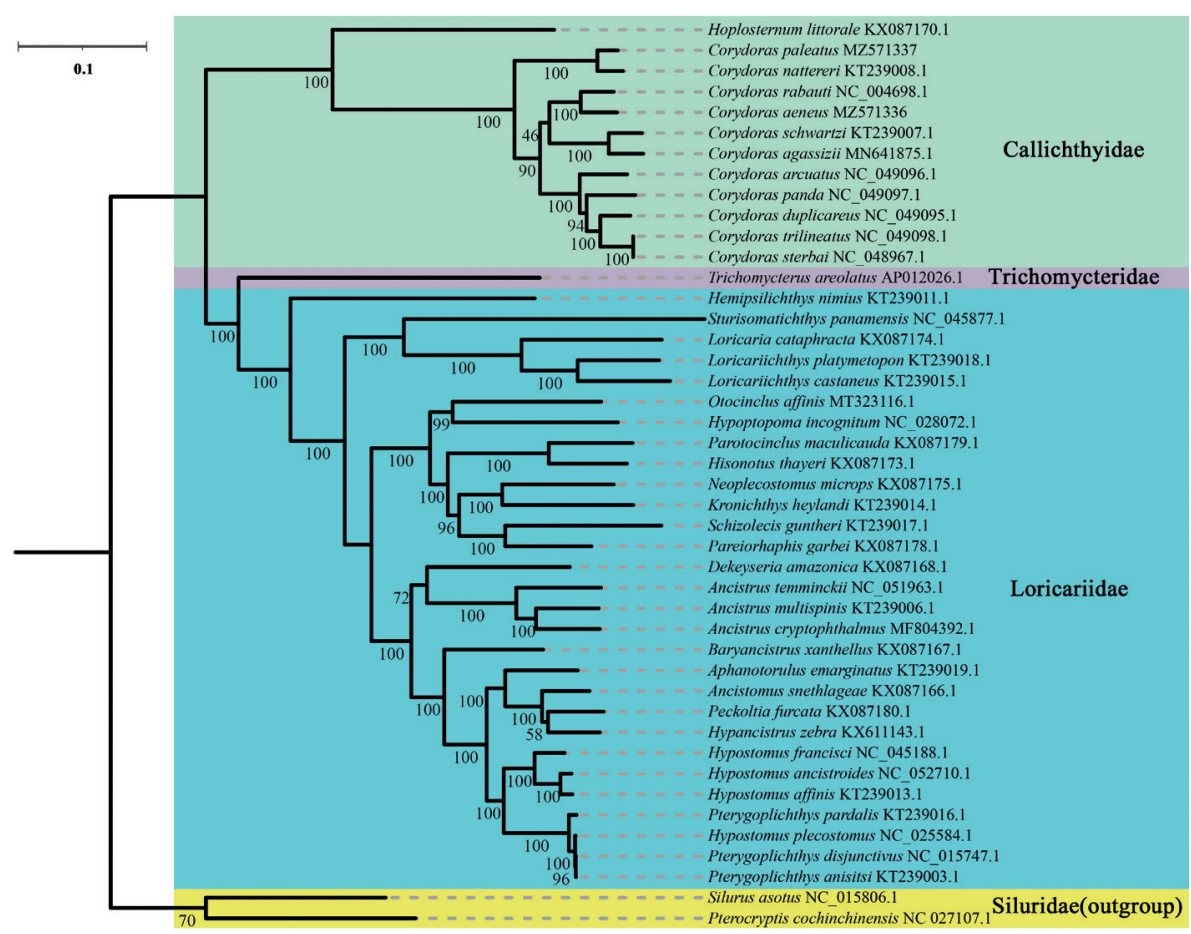

Figure 3. Phylogenetic trees of 44 Siluriformes species using concatenated nucleotide sequences of 13 protein-coding genes and two rRNAs using the maximum likelihood method. Numbers in the ML tree represent SH-aLRT support/ultrafast bootstrap support values. 


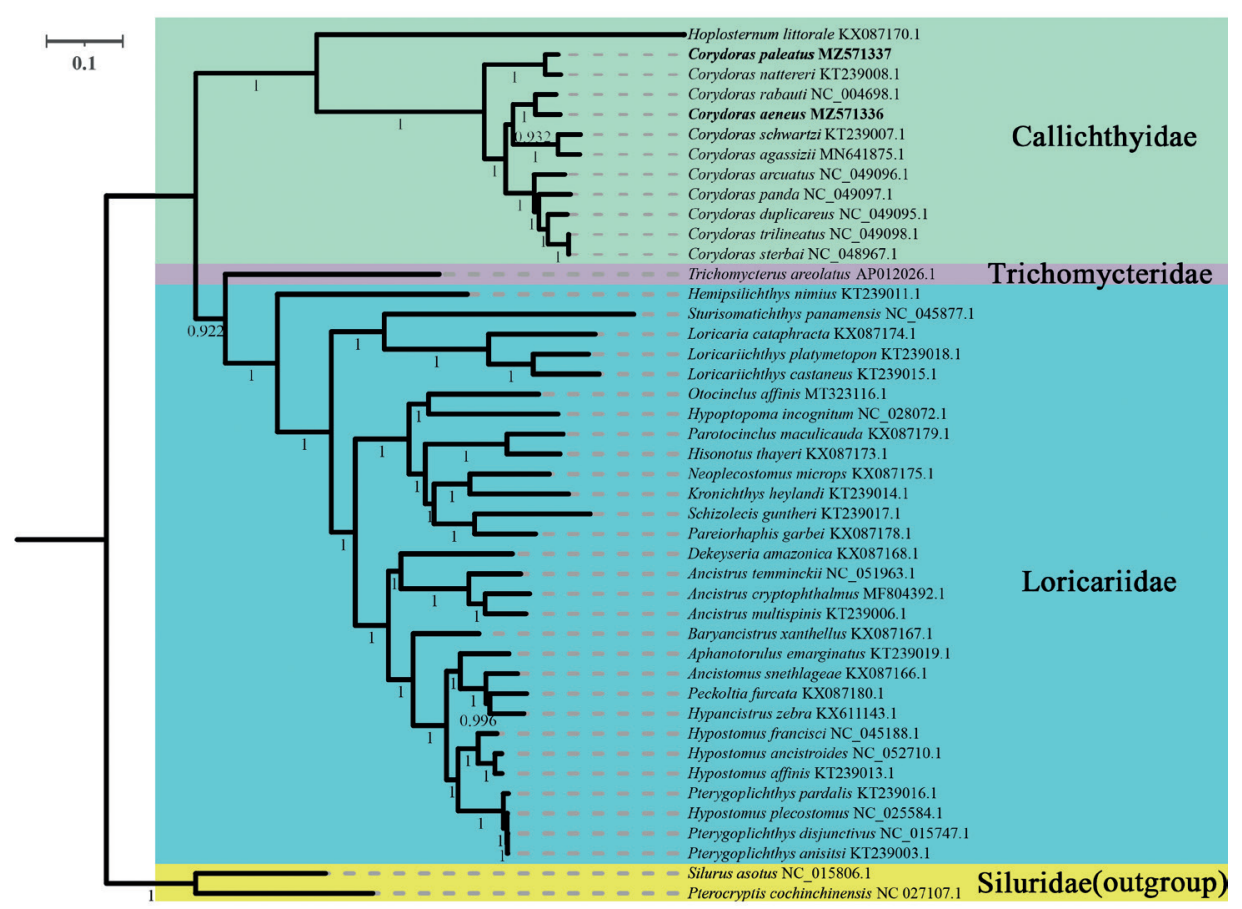

Figure 4. Phylogenetic tree of 44 Siluriformes species using concatenated nucleotide sequences of 13 protein-coding genes and two rRNAs via the Bayesian interference method. Applicable posterior probability values are shown.

species $C$. aeneus and $C$. paleatus were clustered into two clades (C. aeneus $+C$. rabauti) and $(C$. paleatus $+C$. nattereri $)$ with a high nodal support value $(\mathrm{PP}=1 ; \mathrm{BS}=100)$. The eleven species of the genus Corydoras clustered together quite well $[((C$. aeneus $+C$. rabauti $)+($ C. schwartzi $+C$. agassizii $))+($ C. arcuatus $+(C$. panda $+(C$. duplicareus + $($ C. sterbai $+C$. trilineatus $))))]+[(C$. paleatus $+C$. nattereri $)]$. Corydoras trilineatus and C. sterbai have short, almost non-existent branch lengths; thus, they are likely the same species. The K2P genetic distances of these two species are 0.000 (Suppl. material 1: Table S3), which verifies that they are the same species. This may be caused by incorrect identification, taxonomic problems (these two species are, in fact, synonymous), and/ or introgressive hybridization. Moreover, in the family Loricariidae, the genera Ancistrus and Loricariichthys were clustered into monophyletic clades [(A. cryptophthalmus + A. multispinis $)+A$. temminckii $]$ and (L. castaneus + L. platymetopon) with a high nodal support value ( $\mathrm{PP}=1 ; \mathrm{BS}=100)$. There was a paraphyletic relationship between the genera Hypostomus and Pterygoplichthys, [H. francisci + (H. ancistroides + H. affinis), $P$. pardalis $+(H$. plecostomus $+($ P. anisitsi $+P$. disjunctivus $))]$. Our results demonstrate that the concatenated nucleotide sequences of the 13 PCGs and two rRNAs were useful for determining the phylogenetic relationships of the order Siluriformes. These results can be used to improve classification of the families Callichthyidae and Loricariidae. 


\section{Conclusions}

Using next-generation sequencing methods, the complete mitogenomes of the bronze $C$. aeneus and peppered $C$. paleatus were analyzed and compared with those of nine members of Corydoras. The complete mitogenomes of $C$. aeneus and $C$. paleatus comprised 16,604 and 16,593 bp, respectively. The two mitogenomes had high A+T contents $(58.52 \%$ in C. aeneus and $58.23 \%$ in C. paleatus), a phenomenon that agrees with the typical base bias of ichthyic mitogenomes. Our results indicate that the mitogenome features, including genome size, gene content, and gene arrangement, in Corydoras are highly conserved. Phylogenetic analysis was performed with 42 species of Loricarioidei and two outgroup species. These analyses confirmed the occurrence of the genus Corydoras within the monophyletic family Callichthyidae. The complete mitogenome information, including the gene content, gene orders, genome structure, base compositions, evolutionary features, codon usage, gene arrangement, and phylogenetic analyses, provides a basis for future studies on the population genetic and evolution of Corydoras and related groups.

\section{Acknowledgements}

This work was supported by the National Key R\&D Program of China (Grant number 2018YFD0900802); Director's Fund of the Hubei Key Laboratory of Three Gorges Project for Conservation of Fishes, China Three Gorges Corporation (0704157); Outstanding Innovative Talents Cultivation Funded Programs for Doctoral Students of Jinan University (Project No: 2021CXB022) and Priority Academic Program Development of Jiangsu Higher Education Institutions (PAPD). We gratefully acknowledge two reviewers for their constructive comments and would like to thank Editage (www. editage.com) for their support with language editing.

\section{References}

Alexandrou MA, Oliveira C, Maillard M, McGill RA, Newton J, Creer S, Taylor MI (2011) Competition and phylogeny determine community structure in Müllerian co-mimics. Nature 469: 84-88. https://doi.org/10.1038/nature09660

Anderson S, Bankier AT, Barrell BG, de Bruijn MH, Coulson AR, Drouin J, Eperon IC, Nierlich DP, Roe BA, Sanger F, Schreier PH, Smith AJ, Staden R, Young IG (1981) Sequence and organization of the human mitochondrial genome. Nature 290: 457-465. https://doi. org/10.1038/290457a0

Avise JC, Arnold J, Ball RM, Bermingham E, Lamb T, Neigel JE, Reeb CA, Saunders NC (1987) Intraspecific phylogeography: The mitochondrial DNA bridge between population genetics and systematics. Annual Review of Ecology and Systematics 18: 489-522. https:// doi.org/10.1146/annurev.es.18.110187.002421 
Bankevich A, Nurk S, Antipov D, Gurevich AA, Dvorkin M, Kulikov AS, Lesin VM, Nikolenko SI, Pham S, Prjibelski AD, Pyshkin AV, Sirotkin AV, Vyahhi N, Tesler G, Alekseyev MA, Pevzner PA (2012) SPAdes: A new genome assembly algorithm and its applications to single-cell sequencing. Journal of Computational Biology 19: 455-477. https://doi. org/10.1089/cmb.2012.0021

Bartlett SE, Davidson WS (1991) Identification of Thunnus tuna species by the polymerase chain reaction and direct sequence analysis of their mitochondrial cytochrome $b$ genes. Canadian Journal of Fisheries and Aquatic Sciences 48: 309-317. https://doi.org/10.1139/ f91-043

Beheregaray LB, Sunnucks P (2001) Fine-scale genetic structure, estuarine colonization and incipient speciation in the marine silverside fish Odontesthes argentinensis. Molecular Ecology 10: 2849-2866. https://doi.org/10.1046/j.1365-294X.2001.t01-1-01406.x

Bermingham E, Avise JC (1986) Molecular zoogeography of freshwater fishes in the southeastern United States. Genetics 113: 939-965. https://doi.org/10.1007/BF00123216

Brown WM, George M, Wilson AC (1979) Rapid evolution of animal mitochondrial DNA. Proceedings of the National Academy of Sciences 76: 1967-1971. https://doi.org/10.1073/ pnas.76.4.1967

Burland TG (2000) DNASTAR's Lasergene sequence analysis software. In: Misener S, Krawetz SA (Eds) Bioinformatics Methods and Protocols. Methods in Molecular Biology, vol. 132. Humana Press, Totowa, 71-91. https://doi.org/10.1385/1-59259-192-2:71

Chen L, Xu B, Xiao T, Liu Q (2020) Characterization and phylogenetic analysis of Using MUMmer to identify similar regions in large sequence sets Corydoras trilineatus mitochondrial genome. Mitochondrial DNA Part B Resources 5: 3017-3018. https://doi.org/10.1 080/23802359.2020.1797551

Delcher AL, Salzberg SL, Phillippy AM (2003) Using MUMmer to identify similar regions in large sequence sets. Current Protocols in Bioinformatics 00: 10.3.1-10.3.18. https://doi. org/10.1002/0471250953.bi1003s00

De Rijk P, Van de Peer Y, Van den Broeck I, De Wachter R (1995) Evolution according to large ribosomal subunit RNA. Journal of Molecular Evolution 41: 366-375. https://doi. org/10.1007/BF01215184

Gadaleta G, Pepe G, De Candia G, Quagliariello C, Sbisà E, Saccone C (1989) The complete nucleotide sequence of the Rattus norvegicus mitochondrial genome: Cryptic signals revealed by comparative analysis between vertebrates. Journal of Molecular Evolution 28: 497-516. https://doi.org/10.1007/BF02602930

Griffiths-Jones S, Bateman A, Marshall M, Khanna A, Eddy SR (2003) Rfam: An RNA family database. Nucleic Acids Research 31: 439-441. https://doi.org/10.1093/nar/gkg006

Hrbek T, Seckinger J, Meyer A (2007) A phylogenetic and biogeographic perspective on the evolution of poeciliid fishes. Molecular Phylogenetics and Evolution 43: 986-998. https:// doi.org/10.1016/j.ympev.2006.06.009

Huelsenbeck JP, Ronquist F (2001) MRBAYES: Bayesian inference of phylogenetic trees. Bioinformatics 17: 754-755. https://doi.org/10.1093/bioinformatics/17.8.754

Huysentruyt F, Adriaens D (2005a) Descriptive osteology of Corydoras aeneus (Siluriformes: Callichthyidae). Cybium 29: 261-73. 
Huysentruyt F, Adriaens D (2005b) Adhesive structures in the eggs of Corydoras aeneus (Gill 1858; Callichthyidae). Journal of Fish Biology 66: 871-876. https://doi.org/10.1111/ j.0022-1112.2005.00647.x

Ingram S, Munzner T, Olano M (2009) Glimmer: Multilevel MDS on the GPU. IEEE Transactions on Visualization and Computer Graphics 15: 249-261. https://doi.org/10.1109/ TVCG.2008.85

Iwasaki W, Fukunaga T, Isagozawa R, Yamada K, Maeda Y, Satoh TP, Sado T, Mabuchi K, Takeshima H, Miya M, Nishida M (2013) MitoFish and MitoAnnotator: A mitochondrial genome database of fish with an accurate and automatic annotation pipeline. Molecular Biology Evolution 30: 2531-2540. https://doi.org/10.1093/molbev/mst141

Kai Y, Nakayama K, Nakabo T (2002) Genetic differences among three colour morphotypes of the black rockfish, Sebastes inermis, inferred from mtDNA and AFLP analyses. Molecular Ecology 11: 2591-2598. https://doi.org/10.1046/j.1365-294X.2002.01628.x

Kalyaanamoorthy S, Minh BQ, Wong TKF, von Haeseler A, Jermiin LS (2017) ModelFinder: Fast model selection for accurate phylogenetic estimates. Nature Methods 14: 587-589. https://doi.org/10.1038/nmeth.4285

Katoh K, Standley DM (2013) MAFFT multiple sequence alignment software version 7: Improvements in performance and usability. Molecular Biology Evolution 30: 772-780. https://doi.org/10.1093/molbev/mst010

Kumar S, Tamura K, Nei M (1994) MEGA: Molecular evolutionary genetics analysis software for microcomputers. Computer Applications in the Biosciences 10: 189-191. https://doi. org/10.1093/bioinformatics/10.2.189

Letunic I, Bork P (2016) Interactive tree of life (iTOL) v3: An online tool for the display and annotation of phylogenetic and other trees. Nucleic Acids Research 44: W242-W245. https://doi.org/10.1093/nar/gkw290

Librado P, Rozas J (2009) DnaSP v5: A software for comprehensive analysis of DNA polymorphism data. Bioinformatics 25: 1451-1452. https://doi.org/10.1093/bioinformatics/btp187

Lima FCT, Britto MR (2020) A new Corydoras (Ostariophysi: Siluriformes: Callichthyidae) with an unusual sexual dimorphism from the Rio Juruena basin, Brazil. Zootaxa 4742: 518-530. https://doi.org/10.11646/zootaxa.4742.3.6

Liu H, Tzeng CS, Teng HY (2002) Sequence variations in the mitochondrial DNA control region and their implications for the phylogeny of the Cypriniformes. Canadian Journal of Zoology 80: 569-581. https://doi.org/10.1139/z02-035

Liu Q, Liu Y, Xiao T, Xu B (2019a) Complete mitochondrial genome of Corydoras panda (Teleostei, Siluriformes, Callichthyidae, Corydoradinae). Mitochondrial DNA Part B Resources 4: 2878-2879. https://doi.org/10.1080/23802359.2019.1660253

Liu Q, Liu Y, Xu B, Xiao T (2019b) Next-generation sequencing yields the complete mitochondrial genome of Corydoras sterbai (Teleostei, Siluriformes, Callichthyidae, Corydoradinae). Mitochondrial DNA Part B Resources 4: 2880-2881. https://doi.org/10.1080/23 802359.2019 .1660255

Liu Q, Xu B, Xiao T (2019c) Complete mitochondrial genome of Corydoras duplicareus (Teleostei, Siluriformes, Callichthyidae). Mitochondrial DNA Part B Resources 4: 1832-1833. https://doi.org/10.1080/23802359.2019.1612714 
Liu S, Zhang J, Yao J, Liu Z (2016) The complete mitochondrial genome of the armored catfish, Hypostomus plecostomus (Siluriformes: Loricariidae). Mitochondrial DNA Part A DNA Mapping, Sequencing, and Analysis 27: 1908-1909. https://doi.org/10.3109/1940 1736.2014.971281

Liu Y, Xu B, Xiao T, Liu Q (2019d) Characterization and phylogenetic analysis of Corydoras arcuatus mitochondrial genome. Mitochondrial DNA Part B Resources 4: 2876-2877. https://doi.org/10.1080/23802359.2019.1660251

Lowe TM, Eddy SR (1997) TRNAscan-SE: A program for improved detection of transfer RNA genes in genomic sequence. Nucleic Acids Research 25: 955-964. https://doi.org/10.1093/ nar/25.5.955

Lujan NK, Armbruster JW, Lovejoy NR, López-Fernández H (2015) Multilocus molecular phylogeny of the suckermouth armored catfishes (Siluriformes: Loricariidae) with a focus on subfamily Hypostominae. Molecular phylogenetics and evolution 82: 269-288. https://doi.org/10.1016/j.ympev.2014.08.020

Luo R, Liu B, Xie Y, Li Z, Huang W, Yuan J, He G, Chen Y, Pan Q, Liu Y, Tang J, Wu G, Zhang H, Shi Y, Liu Y, Yu C, Wang B, Lu Y, Han C, Wang J (2012) SOAPdenovo2: An empirically improved memory-efficient short-read de novo assembler. GigaScience 1: 18. https://doi.org/10.1186/2047-217X-1-18

Lv L, Su H, Xu B, Liu Q, Xiao T (2020) Complete mitochondrial genome of Corydoras agassizii. Mitochondrial DNA Part B Resources 5: 727-728. https://doi.org/10.1080/238023 59.2020 .1715277

Magalhães MGP, Moreira DA, Furtado C, Parente TE (2017) The mitochondrial genome of Hypancistrus zebra (Isbrücker Nijssen 1991) (Siluriformes: Loricariidae), an endangered ornamental fish from the Brazilian Amazon. Conservation Genetics Resources 9: 319-324. https://doi.org/10.1007/s12686-016-0645-5

Manchado M, Catanese G, Ponce M, Funes V, Infante C (2007) The complete mitochondrial genome of the Senegal sole, Solea senegalensis Kaup. Comparative analysis of tandem repeats in the control region among soles. DNA Sequence 18: 169-175. https://doi. org/10.1080/10425170701308956

Meng F, Yin X, Zhang T, Zhao C, Xue X, Xia X, Zhu X, Duan Z, Liu B, Liu Y (2021) The first determination and analysis of the complete mitochondrial genome of Ancistrus temmincki (Siluriformes: Loricariidae). Mitochondrial DNA Part B Resources 6: 1583-1585. https:// doi.org/10.1080/23802359.2020.1866446

Meyer A (1993) Evolution of mitochondrial DNA in fishes. In: Hochachka PW, Mommsen TP (Eds) Biochemistry and Molecular Biology of Fishes. Elsevier Press, [xxxx,] 1-38.

Michot B, Qu LH, Bachellerie JP (1990) Evolution of large-subunit rRNA structure: The diversification of divergent D3 domain among major phylogenetic groups. European Journal of Biochemistry 188: 219-229. https://doi.org/10.1111/j.1432-1033.1990.tb15393.x

Moreira DA (2018) O que Dados transcriptômicos revelam sobre a biodiversidade e evolução de Loricarioidei (Siluriformes) [Doctoral Dissertation, Instituto Oswaldo Cruz, Fundação Oswaldo Cruz, Rio de Janeiro].

Moreira DA, Buckup PA, Britto MR, Magalhães MGP, de Andrade PCC Furtado C, Parente TE (2016a) The complete mitochondrial genome of Corydoras nattereri (Callichthyidae: Cory- 
doradinae). Neotropical Ichthyology 14(01): e1501670. https://doi.org/10.1590/19820224-20150167

Moreira DA, Buckup PA, Furtado C, Val AL., Schama R, Parente TE (2017) Reducing the information gap on Loricarioidei (Siluriformes) mitochondrial genomics. BMC Genomics 18: 1-13. https://doi.org/10.1186/s12864-017-3709-3

Moreira DA, Magalhães MGP, de Andrade PCC, Furtado C, Val AL, Parente TE (2016b) An RNA-based approach to sequence the mitogenome of Hypoptopoma incognitum (Siluriformes: Loricariidae). Mitochondrial DNA Part A DNA Mapping, Sequencing, and Analysis 27: 3784-3786. https://doi.org/10.3109/19401736.2015.1079903

Nakatani M, Miya M, Mabuchi K, Saitoh K, Nishida M (2011) Evolutionary history of Otophysi (Teleostei), a major clade of the modern freshwater fishes: Pangaean origin and Mesozoic radiation. BMC Evolutionary Biology 11: 177. https://doi.org/10.1186/1471-2148-11-177

Nawrocki EP, Eddy SR (2013) Infernal 1.1: 100-Fold faster RNA homology searches. Bioinformatics 29: 2933-2935. https://doi.org/10.1093/bioinformatics/btt509

O'Brien TW (1971) The general occurrence of $55 \mathrm{~S}$ ribosomes in mammalian liver mitochondria. Journal of Biological Chemistry 246: 3409-3417. https://doi.org/10.1016/S00219258(18)62239-2

Ojala D, Montoya J, Attardi G (1981) tRNA punctuation model of RNA processing in human mitochondria. Nature 290: 470-474. https://doi.org/10.1038/290470a0

Parente TE, Moreira DA, Buckup PA, de Andrade PCC, Magalhães MGP, Furtado C, Britto MR, Val AL (2018) Remarkable genetic homogeneity supports a single widespread species of Hoplosternum littorale (Siluriformes, Callichthyidae) in South America. Conservation Genetics Resources 10: 563-569. https://doi.org/10.1007/s12686-017-0831-0

Parente TE, Moreira DA, Magalhães MGP, de Andrade PCC, Furtado C, Haas BJ, Stegeman JJ, Hahn ME (2017) The liver transcriptome of suckermouth armoured catfish (Pterygoplichthys anisitsi, Loricariidae): Identification of expansions in defensome gene families. Marine Pollution Bulletin 115: 352-361. https://doi.org/10.1016/j.marpolbul.2016.12.012

Pereira AH, Facchin S, Oliveira do Carmo A, Núñez Rodriguez D, Cardoso Resende LC, Kalapothakis Y, Brandáo Dias Ferreira Pinto P, Mascarenhas Alves CB, Henrique Zawadzki C, Kalapothakis E (2019) Complete mitochondrial genome sequence of Hypostomus francisci (Siluriformes: Loricariidae). Mitochondrial DNA Part B Resources 4: 155-157. https:// doi.org/10.1080/23802359.2018.1544860

Pesole G, Gissi C, De Chirico A, Saccone C (1999) Nucleotide substitution rate of mammalian mitochondrial genomes. Journal of molecular evolution 48: 427-434. https://doi. org/10.1007/PL00006487

Popazoglo F, Boeger WA (2000) Neotropical Monogenoidea 37. Redescription of Gyrodactylus superbus (Szidat 1973) comb. n. and description of two new species of Gyrodactylus (Gyrodactylidea: Gyrodactylidae) from Corydoras paleatus and C. ehrhardti (Teleostei: Siluriformes: Callichthyidae) of southern Brazil. Folia Parasitologica 47(2): 105-110. https:// doi.org/10.14411/fp.2000.022

Ranwez V, Douzery EJP, Cambon C, Chantret N, Delsuc F (2018) MACSE v2: toolkit for the alignment of coding sequences accounting for frameshifts and stop codons. Molecular Biology Evolution 35: 2582-2584. https://doi.org/10.1093/molbev/msy159 
Ren F, Chen D, Ma X (2019) The complete mitochondrial genome of Sturisomatichthys panamense (Siluriformes: Loricariidae) analysed by next-generation sequencing and phylogeny of the catfish subfamily Loricariinae (Siluriformes: Loricariidae). Biologia 75: 1365-1372. https://doi.org/10.2478/s11756-019-00389-7

Resende LC, Carmo AOd, Núñez-Rodriguez D, Pimentel JdSM, Bedore AG, Leal HG, Kalapothakis E (2016) Pimelodus maculatus (Siluriformes, Pimelodidae): Complete mtDNA sequence of an economically important fish from the São Francisco river basin. Mitochondrial DNA Part B Resources 1: 806-808. https://doi.org/10.1080/23802359.2016.1219 646

Rocha-Reis DA, Pasa R, Menegidio FB, Heslop-Harrison JS, Schwarzacher T, Kavalco KF (2020) The complete mitochondrial genome of two armored catfish populations of the genus Hypostomus (Siluriformes, Loricariidae, Hypostominae). Frontiers in Ecology and Evolution 8: e579965. https://doi.org/10.3389/fevo.2020.579965

Roxo FF, Ochoa LE, Sabaj MH, Lujan NK, Covain R, Silva GS, Oliveira C (2019) Phylogenomic reappraisal of the Neotropical catfish family Loricariidae (Teleostei: Siluriformes) using ultraconserved elements. Molecular Phylogenetics and Evolution 135: 148-165. https://doi.org/10.1016/j.ympev.2019.02.017

Saitoh K, Miya M, Inoue JG, Ishiguro NB, Nishida M (2003) Mitochondrial genomics of ostariophysan fishes: Perspectives on phylogeny and biogeography. Journal of Molecular Evolution 56: 464-472. https://doi.org/10.1007/s00239-002-2417-y

Simon C, Frati F, Beckenbach A, Crespi B, Liu H, Flook P (1994) Evolution, weighting, and phylogenetic utility of mitochondrial gene sequences and a compilation of conserved polymerase chain reaction primers. Annals of the Entomological Society of America 87: 651701. https://doi.org/10.1093/aesa/87.6.651

Tencatt LFC, Dos Santos SA, Evers HG, Britto MR (2021) Corydoras fulleri (Siluriformes: Callichthyidae), a new catfish species from the Rio Madeira basin, Peru. Journal of Fish Biology 99(2): 614-628. https://doi.org/10.1111/jfb.14750

Watanabe S (2013) A widely applicable Bayesian information criterion. Journal of Machine Learning Research 14: 867-897.

Wolstenholme DR (1992) Animal mitochondrial DNA: Structure and evolution. International Review of Cytology 141: 173-216. https://doi.org/10.1016/S0074-7696(08)62066-5

Xu B, Su H, Liu Q, Lv L, Chen K, Xiao T (2020) Complete mitochondrial genome of Brochis multiradiatus. Mitochondrial DNA Part B Resources 5: 646-647. https://doi.org/10.108 0/23802359.2019.1711227

Xu TJ, Cheng YZ, XZ, Liu GS, Wang RX (2011) The complete mitochondrial genome of the marbled rockfish Sebastiscus marmoratus (Scorpaeniformes, Scorpaenidae): Genome characterization and phylogenetic considerations. Molekulyarnaya Biologiya (Mosk) 45: 392-403. https://doi.org/10.1134/S0026893311020191

Yoshizawa K, Johnson KP (2003) Phylogenetic position of Phthiraptera (Insecta: Paraneoptera) and elevated rate of evolution in mitochondrial $12 S$ and $16 \mathrm{~S}$ rDNA. Molecular Phylogenetics and Evolution 29: 102-114. https://doi.org/10.1016/S1055-7903(03)00073-3

Zhang D, Gao F, Jakovlić I, Zou H, Zhang J, Li WX, Wang GT (2020) PhyloSuite: An integrated and scalable desktop platform for streamlined molecular sequence data manage- 
ment and evolutionary phylogenetics studies. Molecular Ecology Resources 20: 348-355. https://doi.org/10.1111/1755-0998.13096

Zhang K, Liu Y, Chen J, Zhang H, Gong L, Jiang L, Liu L, Lü Z, Liu B (2021) Characterization of the complete mitochondrial genome of Macrotocinclus affinis (Siluriformes; Loricariidae) and phylogenetic studies of Siluriformes. Molecular Biology Reports 48: 677-689. https://doi.org/10.1007/s11033-020-06120-z

\section{Supplementary material I}

COI sequences of Corydoras aeneus and $C$. paleatus Tables S1-S4, Figs S1-S4

Authors: Cheng-He Sun, Qi Huang, Xiao-Shu Zeng, Sha Li, Xiao-Li Zhang, Ya-Nan Zhang, Jian Liao, Chang-Hu Lu, Bo-Ping Han, Qun Zhang

Data type: docx file

Explanation note: COI sequences of Corydoras aeneus and C. paleatus. Table S1. Best substitution models for Bayesian inference (BI) and maximum-likelihood (ML) analyses. Table S2. Summarized mitogenomic characteristics of the eleven Corydoras species investigated in this study. Table S3. The K2P genetic distances of the eleven mitogenomes of Corydoras. Table S4. Start and stop codons of protein-coding genes in the eleven Corydoras mitogenomes. Figure S1. Gene orders of mitogenomes of the studied species. Figure S2. Relative synonymous codon usage of 13 proteincoding genes in the mitogenomes of eleven Corydoras species. Figure S3. Codon usage patterns of eleven Corydoras mitogenomes. Figure S4. Secondary structures of tRNA-Ser(GCT) in the two newly sequenced Corydoras species.

Copyright notice: This dataset is made available under the Open Database License (http://opendatacommons.org/licenses/odbl/1.0/). The Open Database License $(\mathrm{ODbL})$ is a license agreement intended to allow users to freely share, modify, and use this Dataset while maintaining this same freedom for others, provided that the original source and author(s) are credited.

Link: https://doi.org/10.3897/zookeys.1083.76887.suppl1 